\title{
Coronary Microcirculation Remodeling in Patients with Idiopathic Dilated Cardiomyopathy
}

\author{
Rubén Laguens ${ }^{a}$ Paulino Alvarez ${ }^{a} \quad$ Carlos Vigliano $^{a}$ Patricia Cabeza Meckert ${ }^{a}$ \\ Liliana Favaloro $^{b}$ Mirta Diez $^{\text {b }}$ Roberto Favaloro ${ }^{b}$ \\ Departments of ${ }^{\mathrm{a}}$ Pathology and ${ }^{\mathrm{b}}$ Intrathoracic Transplantation, University Hospital Favaloro Foundation, \\ Buenos Aires, Argentina
}

For editorial comments see p. 204 and p. 206

\section{Key Words}

Microcirculation · Pathology $\cdot$ Cardiomyopathy

\begin{abstract}
Background: In patients with idiopathic dilated cardiomyopathy (IDCM), the myocardial blood flow is markedly depressed. The presence of alterations in the number and length of the coronary microcirculation has not been explored. Methods: In explanted hearts of 6 patients with IDCM and in 6 normal control hearts, the arteriolar length density and capillary numerical density were determined in sections stained with orcein (vessels 50-200 $\mu \mathrm{m}$ in diameter), for smooth muscle actin (vessels 6-50 $\mu \mathrm{m}$ in diameter) and CD34 (capillaries). Results: No difference with normal hearts was observed in capillary numerical density and in length density of vessels above $50 \mu \mathrm{m}$ in diameter. In IDCM, more than $50 \%$ of arterioles below $50 \mu \mathrm{m}$ in diameter displayed an incomplete smooth muscle wall, and length density, especially for arterioles between 6 and $20 \mu \mathrm{m}$ in diameter, was significantly lower $\left(42.84 \pm 8.51 \mathrm{~mm} / \mathrm{mm}^{3}\right)$ than in controls $\left(75.34 \pm 3.05 \mathrm{~mm} / \mathrm{mm}^{3}, p=0.001\right)$. Conclusions: In IDCM, arterioles below $50 \mu \mathrm{m}$ in diameter display an incomplete smooth muscle wall and a significant decrease in length density. These observations provide an anatomical basis for a decreased coronary flow reserve in IDCM.
\end{abstract}

Copyright $\odot 2011$ S. Karger AG, Basel

\section{KARGER}

Fax +4161306 1234 E-Mail karger@karger.ch www.karger.com
(C) 2011 S. Karger AG, Basel 0008-6312/11/1194-0191\$38.00/0

Accessible online at:

www.karger.com/crd
Idiopathic dilated cardiomyopathy (IDCM) mainly affects left-ventricle systolic function. Although its incidence is not as high as that of other specific forms of dilated cardiopathy, such as ischemic, toxic (alcoholic), metabolic or hypertensive [1], it represents one of the most frequent indications for heart transplantation [2].

The mechanisms involved in the progressive deterioration of cardiac function are largely unknown. As dysfunction of the coronary microvessels is present since the early onset of the disease, it has been proposed that an impairment of coronary endothelial function [3], as part of a systemic alteration of the vascular endothelium [4], may be responsible of the marked decrease in coronary flow reserve, and may participate in the evolution towards heart failure $[5,6]$.

We hypothesized that dysfunction may be based on structural alterations, similar to those present in hypertensive and hypertrophic cardiomyopathies [7-9]. We report herein that in hearts from IDCM patients who underwent heart transplantations, the walls of arterioles measuring less than $50 \mu \mathrm{m}$ in diameter present an incomplete smooth muscle middle layer and their length density, especially of those measuring 6-20 $\mu \mathrm{m}$ in diameter, is significantly decreased.

Rubén Laguens

Department of Pathology, Hospital Universitario Fundación Favaloro

Avda. Belgrano 1746

Buenos Aires 1093 (Argentina)

Tel. +54 114378 1315, E-Mail rlaguens@ffavaloro.org 
Table 1. Clinical, echocardiographic, hemodynamic and pathological data of IDCM patients

\begin{tabular}{|c|c|c|c|c|c|c|c|}
\hline & \multicolumn{6}{|c|}{ Patients } & \multirow[t]{2}{*}{ Totals } \\
\hline & 1 & 2 & 3 & 4 & 5 & 6 & \\
\hline \multicolumn{8}{|l|}{ Clinical data } \\
\hline Gender & male & female & male & male & female & male & males $4 / 6(66.7 \%)$ \\
\hline Age, years & 15 & 26 & 46 & 19 & 15 & 44 & $27.5 \pm 14.1$ \\
\hline LVEF, \% & 13 & 7 & 16 & 14 & 14 & 12 & $12.6 \pm 3.4$ \\
\hline Mitral regurgitation (moderate-severe) & yes & yes & yes & no & no & yes & $4 / 6(66.7 \%)$ \\
\hline \multicolumn{8}{|l|}{ Echocardiographic data } \\
\hline LVEDD, mm & 71 & 75 & 97 & 68 & 72 & 83 & $77.7 \pm 10.8$ \\
\hline LVESD, mm & 61 & 67 & 80 & 57 & 68 & 72 & $67.5 \pm 8.1$ \\
\hline IVST, mm & 9 & 8 & 6 & 7 & 6 & 6 & $7.0 \pm 1.3$ \\
\hline PWT, mm & 9 & 8 & 7 & 8 & 9 & 10 & $8.5 \pm 1.1$ \\
\hline $\mathrm{LAD}, \mathrm{mm}$ & 54 & 36 & 50 & 41 & 43 & 41 & $44.1 \pm 6.6$ \\
\hline \multicolumn{8}{|l|}{ Hemodynamic data } \\
\hline Mean PAP, mm Hg & 40 & 13 & 38 & 32 & 12 & 28 & $27.5 \pm 12.1$ \\
\hline $\mathrm{PAW}, \mathrm{mm} \mathrm{Hg}$ & 33 & 15 & 29 & 16 & 8 & 20 & $20.2 \pm 9.3$ \\
\hline $\mathrm{RA}, \mathrm{mm} \mathrm{Hg}$ & 6 & 1 & 4 & 3 & 1 & 5 & $3.3 \pm 2.1$ \\
\hline $\mathrm{CI}$, liters $/ \mathrm{min} / \mathrm{m}^{2}$ & 1.2 & 2.1 & 2.4 & 2.2 & 3.9 & 2.5 & $2.4 \pm 0.9$ \\
\hline \multicolumn{8}{|l|}{ Pathological findings } \\
\hline Heart weight, g & 340 & 315 & 680 & 345 & 355 & 630 & $445.0 \pm 164.0$ \\
\hline Fibrosis, $\%$ & 17.5 & 13.7 & 12.5 & 12.4 & 9.0 & 16.7 & $13.6 \pm 3.1$ \\
\hline
\end{tabular}

LVEF = Left ventricular ejection fraction; LVEDD = left ventricular end-diastolic diameter; LVESD = left ventricular end-systolic diameter; IVST = interventricular septal wall thickness; PWT = left ventricular posterior wall thickness; LAD = left atrial diameter; $\mathrm{PAP}=$ pulmonary artery pressure; $\mathrm{PAW}=$ pulmonary artery wedge; $\mathrm{RA}=$ right atrium pressure; $\mathrm{CI}=$ cardiac index.

\section{Methods}

\section{Study Samples}

Six hearts explanted from patients who underwent heart transplantations because of end-stage IDCM were studied. IDCM was defined as ventricular enlargement, normal wall thickness and systolic dysfunction with a left-ventricle ejection fraction $<30 \%$ in the absence of coronary artery disease as assessed by coronary arteriography [10].

The control group consisted of 6 beating hearts with no evidence of structural heart disease, excluded from heart transplantation because of excessive intake of inotropic drugs and an ischemia time $<4 \mathrm{~h}$, but who were suitable for providing valves for homograft transplantation.

The investigation conforms to the principles outlined in the Declaration of Helsinki. Demographic and main clinical data of patients are summarized in table 1.

\section{Tissue Preparation}

The right-ventricle free wall and atria were removed from all hearts and the weight of the left ventricle, including the interventricular septum, was recorded. The left ventricle was fixed by immersion in $10 \%$ buffered formaldehyde. The time elapsed between removal of the hearts and fixation was $1-6 \mathrm{~h}$ for the IDCM hearts and $12-24 \mathrm{~h}$ for control hearts kept at $4^{\circ} \mathrm{C}$ during that time.

After 7-14 days of fixation, the left ventricle was sectioned transversally at a plane equidistant from the base and the apex, and a 5-mm-thick tissue block of the lateral wall extending from the endocardium to the epicardium was embedded in paraffin.

Three-micrometer-thick tissue sections were stained with orcein for identification of the internal elastic lamina of arteries measuring 50-300 $\mu \mathrm{m}$ in diameter. For identification of smaller vessels, tissue sections were incubated with specific monoclonal antibodies against smooth muscle actin for small arterioles and CD34 antigen for capillary endothelium.

After incubation with the monoclonal antibodies (Biogenex, San Ramon, Calif., USA), the sections were posttreated with biotin-labeled anti-mouse immunoglobulin antibody and revealed with peroxidase-conjugated streptavidin using AEC (3-amino-9ethyl carbazole) as chromogen (Biogenex).

\section{Microvascular Morphometry}

All arteries measuring 50-200 $\mu \mathrm{m}$ in diameter (vessels with a patent internal elastic lamina; fig. 1a) present in the whole tissue section in an area of $195-334 \mathrm{~mm}^{2}$ were captured under $100 \times$ magnification. Every artery $<50 \mu \mathrm{m}$ in diameter (vessels with a smooth muscle $\alpha$-actin positive outline) was similarly captured under $250 \times$ magnification in 20 randomly selected areas throughout the endocardium, mesocardium and epicardium, representing $3 \mathrm{~mm}^{2}$ in total area.

In all arteries, independent of their sectioning plane, the long and short axis diameters were measured with a digital analysis system (Image Pro Plus 4.5, Media Cybernetics, LP, Silver Spring, Md., USA). The measurements were done from the limit between 
Fig. 1. a Low-power view of an orceinstained tissue section. The large arterioles exhibit a patent elastic lamina (arrows). b The capillary endothelium is intensely stained with an anti-CD31 antibody. c-f The smooth muscle cells of the small vessels are intensely stained with an antismooth muscle actin antibody. At low magnification, the difference in arteriole number between the IDCM heart (c) and the control heart (d) is readily visible. e Small arteries of an IDCM heart with areas of naked endothelium at higher magnification. In comparison, the vessels of a control heart (f) show a well-developed muscular layer. a Scale bar $=100 \mu \mathrm{m}$. b-d Scale bar $=50 \mu \mathrm{m}$. e, $\mathbf{f}$ Scale bar $=$ $10 \mu \mathrm{m}$.
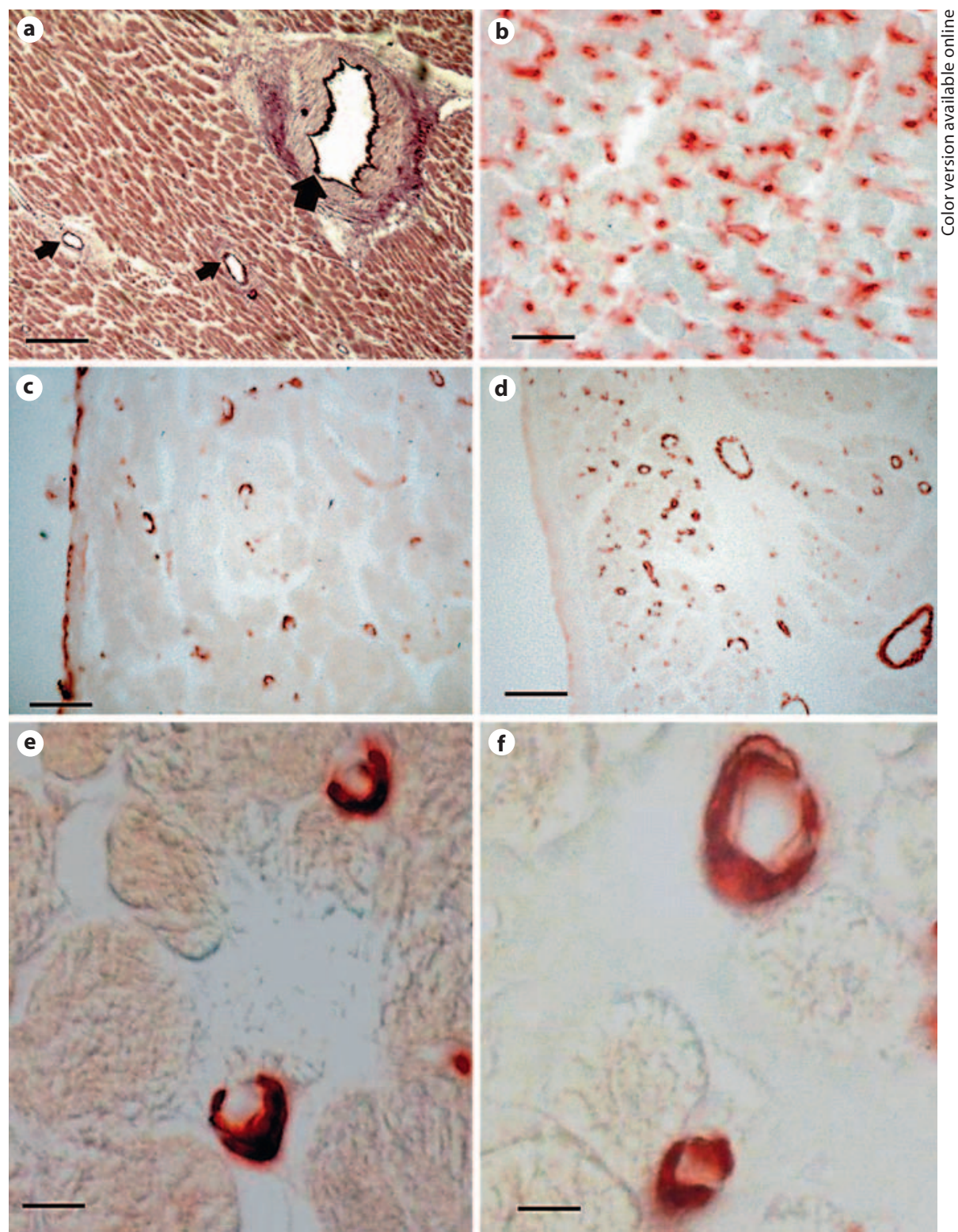

the vessel and the surrounding stroma. Numerical density was expressed as the number of vessels by unit area.

Arteriolar length density, average length of arterioles per unit myocyte volume, in millimeters per cubic millimeter was calculated on the basis of the following formula developed for the analysis of arterioles arranged in any orientation [11]: $(\Sigma \mathrm{a} / \mathrm{b}) / \mathrm{N} \cdot \mathrm{N} / \mathrm{A}$, where $\mathrm{a}=$ long axis; $\mathrm{b}=$ short axis of individual arterioles; $\mathrm{N}=$ total number of vessels in total area (A) in which arterioles were measured.

For capillaries (vessels $<6 \mu \mathrm{m}$ in diameter with no middle layer) only the numerical density was recorded (fig. 1b).

All data were referenced to myocyte area rather than to tissue area. This eliminated any errors due to shrinkage or separation artifacts and related arterioles to viable, at-risk myocytes.

\section{Statistical Analysis}

Continuous variables are presented as means \pm standard deviations; categorical variables are presented as percentages of all patients. The Kolmogorov-Smirnov test was used to examine the distribution of the continuous variables. The continuous variables with a Gaussian distribution (age and heart weight) were analyzed by Student's t test.

The continuous variables with a non-Gaussian distribution (length density and numerical density) were analyzed by the Mann-Whitney test. Fisher's exact test was used to compare categorical variables. The pathological and clinical data were analyzed using the SPSS ${ }^{\circledR} 11.0$ software (SPSS Inc., Chicago, Ill., USA). 
Fig. 2. The length density of vessels between 6 and $20 \mu \mathrm{m}$ is significantly lower in IDCM hearts. There were no statistically significant differences between the length density of larger arterioles and capillary number between IDCM and normal hearts.

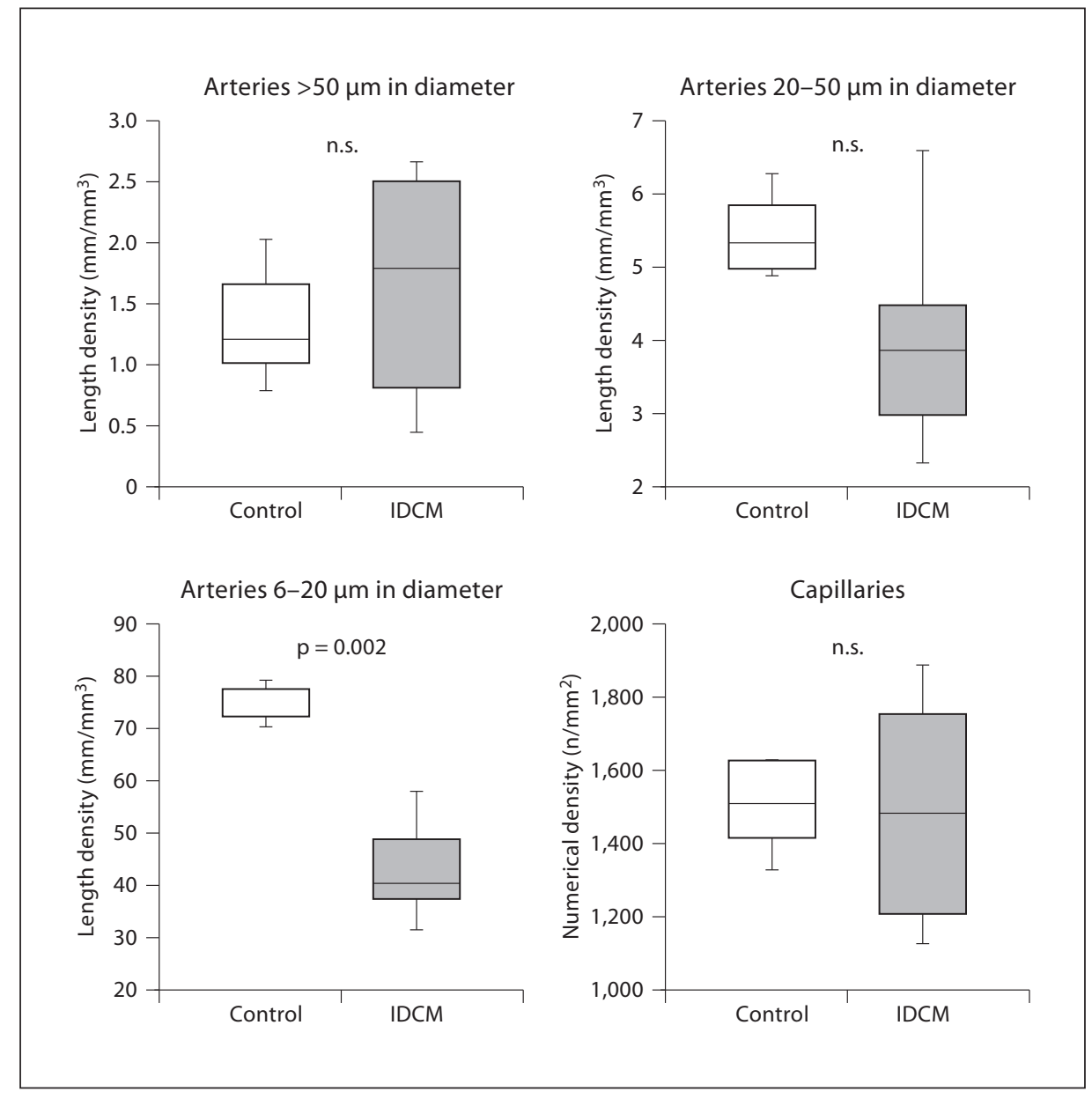

\section{Results}

There were no statistical differences between the IDCM and control groups with regard to age $(27.5 \pm 14.1$ vs. $27.8 \pm 12.0$ years, respectively) and sex (4/6 vs. $3 / 6$ males, respectively). The average weight of the 6 IDCM hearts analyzed was $445.0 \pm 164.0 \mathrm{~g}$, and that of the 6 controls was $263.3 \pm 54.5 \mathrm{~g}(\mathrm{p}=0.042)$.

The length density of all arteries measuring 6-200 $\mu \mathrm{m}$ in diameter was significantly lower in the IDCM hearts compared to control hearts $(\mathrm{p}=0.004)$. Figure $1 \mathrm{c}$ shows a representative image of the decreased number of small vessels in IDCM as compared with a normal heart (fig. 1d). As can be seen in figure 2, this was due almost exclusively to a decrease in length density of the arteries measuring 6-20 $\mu \mathrm{m}$ in diameter $\left(42.84 \pm 9.33 \mathrm{~mm} / \mathrm{mm}^{3}\right.$ in IDCM and $75.52 \pm 3.42 \mathrm{~mm} / \mathrm{mm}^{3}$ in controls, $\mathrm{p}=$ $0.004)$.
On the contrary, the length density of larger arterioles (51-200 $\mu \mathrm{m}$ in diameter) was similar in both groups.

As opposed to the findings on small arteries, no differences were found in capillary numerical density between IDCM and control hearts (fig. 2).

Figure $1 c-f$ shows images of arteries measuring 6-50 $\mu \mathrm{m}$ in diameter stained with an anti-smooth-muscle actin antibody. As can be seen in figure 1e, many vessels of that size exhibited an incomplete middle layer as compared with vessels of similar size of normal hearts (fig. 1f). Although this alteration of the vessel wall was present in all the IDCM hearts, there were individual variations. The proportion of arterioles measuring $<50 \mu \mathrm{m}$ in diameter with an incomplete muscle layer ranged between 52 and $83 \%$. In the control normal hearts, arterioles of similar size and with an incomplete smooth muscle layer represented less than $10 \%$ of all vessels. 


\section{Discussion}

The main findings of our study are that in hearts explanted from patients with IDCM, who underwent a heart transplantation, the smallest-resistance arterioles show a significant decrease in length density associated with frank alterations of the smooth muscle wall.

The results of the morphometric study are remarkably similar to observations made almost 20 years ago in rats with left-ventricular failure after long-standing experimentally induced renal hypertension [12], showing that the length densities of resistance vessels from 6 to $40 \mu \mathrm{m}$ in luminal diameter were markedly decreased. In addition, as in our study, the capillary numerical density was not altered, indicating a significant amount of capillary proliferation.

As opposed to our findings, a marked decrease in the number of capillaries in IDCM was reported [13]. This discrepancy could be ascribed to the techniques employed for measuring vessels (morphology of thin sections of epoxy resin-embedded samples vs. immunohistochemical demonstration of endothelial cell markers in paraffin-embedded tissue) and to the different size and location of the heart areas employed for the studies.

More than 15 years ago, it was reported that in IDCM explanted hearts, the myocardial blood flow was markedly depressed [14]. As structural microvessel abnormalities had never been documented in IDCM, it was proposed that the alterations in myocardial blood flow may be due to endothelial dysfunction which, by limiting the coronary vasodilator response to stress, is potentially able to cause an imbalance between myocardial oxygen demand and blood flow. These microcirculatory abnormalities are independent of atherosclerotic lesions of the large epicardial arteries or of abnormalities of the myocytic and interstitial components of myocardial tissue. Altered microvessels are able to limit myocardial perfusion and potentially cause myocardial ischemia [15].

Moreover, it has been reported that the extent of coronary microcirculatory dysfunction in patients with earlystage IDCM is an independent predictor of a poor prognosis $[16,17]$.

We found structural and morphometric alterations in small arteries. More than $50 \%$ of arterioles $<50 \mu \mathrm{m}$ in diameter displayed an incomplete middle layer with disappearance of smooth muscle cells, a phenomenon that was not present in normal control hearts, and the length density of vessels measuring between 6 and $20 \mu \mathrm{m}$ in diameter was almost half of that in controls. The length density of larger arterioles was similar to that of normal hearts, however, indicating that vessels of that size may be able to remodel. This, in turn, suggests that in IDCM, resistance arterioles respond differently to remodeling stimuli: larger intramyocardial arteries would increase their length, but this would not be the case for smaller arteries, which apparently are unable to adapt to organ hypertrophy.

However, the decreased numerical and length densities of precapillary arterioles could also be ascribed to a complete loss of smooth muscle cells in the vessel wall, a phenomenon that would prevent identification of those vessels for morphometric measurements. This smooth muscle loss, represented as incompleteness of the middle layer, could be related to the diminished coronary reserve in IDCM patients since a lack of these cells transforms vessels into rigid tubes, unable to respond to vasodilator stimuli.

In agreement with our results, a significant decrease in the number of vessels $<200 \mu \mathrm{m}$ in diameter in the epicardium, but not in the endocardium, was recently reported in IDCM hearts [18]. However, in that study, no differences were determined between capillary and arterioles and differences according to vessel size were not assessed.

There are scarce published studies on the length density of the arteriolar beds in pathological human hearts; based on the available information it cannot be established whether the arteriolar alterations are only found in IDCM. However, a recent study reported a significant decrease in the length density of arterioles measuring 6-15 $\mu \mathrm{m}$ in diameter in cyanotic congenital heart disease as compared with normal and hypertrophied hearts [19]; this observation suggests that coronary microvascular alterations may be present in other pathologies and participate in the pathogenic mechanisms involved in the evolution of ventricular dysfunction towards heart failure.

As it has been reported that in hearts of patients with dilated cardiomyopathy there is a selective downregulation of VEGF and VEGFr [13] and that transfection of chronically ischemic pig hearts with the human VEGF165 gene induces arteriolar hyperplasia [20], the possibility that the coronary microcirculation may be a new therapeutic target in heart failure should be considered. This is supported by experimental studies showing that disruption of coordinated tissue growth and angiogenesis contributes to the progression from adaptive hypertrophy to heart failure [21].

\section{Study Limitations}

The main limitation of the present study is the small number of patients. This prevented us from studying any relationship between the duration of symptoms and the 
morphometric findings. Nevertheless, all patients had severe heart failure, ejection fraction $<20 \%$ and left-ventricular dilatation. The possibility that the longer time elapsed before fixation of control hearts versus pathological hearts could have influenced the results seems unlikely since control hearts were kept at $4^{\circ} \mathrm{C}$ during that time.

\section{Conclusion}

In IDCM, arterioles $<20 \mu \mathrm{m}$ in diameter show a significant decrease in length density; vessels $<50 \mu \mathrm{m}$ in diameter present clearcut alterations in the smooth muscle wall. Coronary microcirculation remodeling may contribute to decreased flow reserve.

\section{References}

$\checkmark 1$ Elliott P, Andersson B, Arbustini E, Bilinska Z, Cecchi F, Charron P, Dubourg O, Kuhl U, Maisch B, McKenna WJ, Monserrat L, Pankuweit S, Rapezzi C, Seferovic P, Tavazzi L, Keren A: Classification of the cardiomyopathies: a position statement from the European Society of Cardiology Working Group on Myocardial and Pericardial Diseases. Eur Heart J 2008;29:270-276.

$\checkmark 2$ Dec GW, Fuster V: Idiopathic dilated cardiomyopathy. N Engl J Med 1994;331:15641575.

-3 Treasure CB, Vita JA, Cox DA, Fish RD, Gordon JB, Mudge GH, Colucci WS, Sutton MG, Selwyn AP, Alexander RW: Endotheliumdependent dilation of the coronary microvasculature is impaired in dilated cardiomyopathy. Circulation 1990;81:772-779.

4 Drexler H, Hayoz D, Munzel T, Hornig B, Just H, Brunner HR, Zelis R: Endothelial function in chronic congestive heart failure. Am J Cardiol 1992;69:1596-1601.

5 van den Heuvel AF, van Veldhuisen DJ, van der Wall EE, Blanksma PK, Siebelink HM, Vaalburg WM, van Gilst WH, Crijns HJ: Regional myocardial blood flow reserve impairment and metabolic changes suggesting myocardial ischemia in patients with idiopathic dilated cardiomyopathy. J Am Coll Cardiol 2000;35:19-28.

6 Roura S, Bayes-Genis A: Vascular dysfunction in idiopathic dilated cardiomyopathy. Nat Rev Cardiol 2009;6:590-598.

$\checkmark 7$ Maron BJ, Wolfson JK, Epstein SE, Roberts WC: Intramural ('small vessel') coronary artery disease in hypertrophic cardiomyopathy. J Am Coll Cardiol 1986;8:545-557.
-8 Tanaka M, Fujiwara H, Onodera T, Wu DJ, Matsuda M, Hamashima Y, Kawai C: Quantitative analysis of narrowings of intramyocardial small arteries in normal hearts, hypertensive hearts, and hearts with hypertrophic cardiomyopathy. Circulation 1987;75: 1130-1139.

$\checkmark 9$ Fernandez A, Vigliano CA, Casabe JH, Diez M, Favaloro LE, Guevara E, Favaloro RR, Laguens RP: Comparison of prevalence, clinical course, and pathological findings of left ventricular systolic impairment versus normal systolic function in patients with hypertrophic cardiomyopathy. Am J Cardiol 2011;108:548-555.

10 Elliott P: Cardiomyopathy. Diagnosis and management of dilated cardiomyopathy. Heart 2000;84:106-112.

- 11 Adair TH, Wells ML, Hang J, Montani JP: A stereological method for estimating length density of the arterial vascular system. Am J Physiol 1994;266:H1434-H1438.

12 Anversa P, Capasso JM: Loss of intermediate-sized coronary arteries and capillary proliferation after left ventricular failure in rats. Am J Physiol 1991;260:H1552-H1560.

13 Abraham D, Hofbauer R, Schafer R, Blumer R, Paulus P, Miksovsky A, Traxler H, Kocher A, Aharinejad S: Selective downregulation of VEGF-A $A_{165}$, VEGF-R 1 , and decreased capillary density in patients with dilative but not ischemic cardiomyopathy. Circ Res 2000;87: 644-647.

14 Parodi O, De Maria R, Oltrona L, Testa R, Sambuceti G, Roghi A, Merli M, Belingheri L, Accinni R, Spinelli F: Myocardial blood flow distribution in patients with ischemic heart disease or dilated cardiomyopathy undergoing heart transplantation. Circulation 1993;88:509-522.

-15 Neglia D, L’Abbate A: Coronary microvascular dysfunction and idiopathic dilated cardiomyopathy. Pharmacol Rep 2005;57 (suppl):151-155.
16 Rigo F, Gherardi S, Galderisi M, Sicari R, Picano E: The independent prognostic value of contractile and coronary flow reserve determined by dipyridamole stress echocardiography in patients with idiopathic dilated cardiomyopathy. Am J Cardiol 2007;99: 1154-1158.

17 Morales MA, Neglia D, L'Abbate A: Reduction of myocardial blood flow reserve in idiopathic dilated cardiomyopathy without overt heart failure and its relation with functional indices: An echo-Doppler and positron emission tomography study. J Cardiovasc Med (Hagerstown) 2008;9:778-782.

-18 Roura S, Planas F, Prat-Vidal C, Leta R, Soler-Botija C, Carreras F, Llach A, Hove-Madsen L, Pons Llado G, Farre J, Cinca J, BayesGenis A: Idiopathic dilated cardiomyopathy exhibits defective vascularization and vessel formation. Eur J Heart Fail 2007;9:995-1002.

19 Dedkov EI, Perloff JK, Tomanek RJ, Fishbein MC, Gutterman DD: The coronary microcirculation in cyanotic congenital heart disease. Circulation 2006;114:196-200.

20 Crottogini A, Meckert PC, Vera Janavel G, Lascano E, Negroni J, Del Valle H, Dulbecco E, Werba P, Cuniberti L, Martinez V, De Lorenzi A, Telayna J, Mele A, Fernandez JL, Marangunich L, Criscuolo M, Capogrossi MC, Laguens R: Arteriogenesis induced by intramyocardial vascular endothelial growth factor 165 gene transfer in chronically ischemic pigs. Hum Gene Ther 2003;14: 1307-1318.

21 Shiojima I, Sato K, Izumiya Y, Schiekofer S, Ito M, Liao R, Colucci WS, Walsh K: Disruption of coordinated cardiac hypertrophy and angiogenesis contributes to the transition to heart failure. J Clin Invest 2005;115:21082118. 